\title{
Iron Oxide and Sulfide Nanocrystals as Biomarkers
}

\author{
P.R. Buseck,* M. Pósfai, ** R.E. Dunin-Borkowski, *** and M. Weyland ***
}

* Departments of Geological Sciences and Chemistry/ Biochemistry, Arizona State University, Tempe, Arizona 85287-1404

** Department of Earth and Environmental Sciences, University of Veszprém, POB 158, H-8201, Hungary

*** Department of Materials Science and Metallurgy, University of Cambridge, Pembroke Street, Cambridge CB2 3QZ, United Kingdom

Magnetotactic bacteria form intracellular magnetic crystals of iron oxide or iron sulfide, which are used as internal compasses for orienting the cells in aquatic environments. It has been suggested that nanometer-scale magnetite $\left(\mathrm{Fe}_{3} \mathrm{O}_{4}\right)$ and greigite $\left(\mathrm{Fe}_{3} \mathrm{~S}_{4}\right)$ crystals from geological environments, such as the magnetite crystals elongated along $<111>$ that occur in Martian meteorite ALH84001, may be used as biosignatures to provide an indication of the presence of former life. In order to ascertain the biogenic or inorganic origin of such minerals, it is necessary to understand the process of biologically controlled mineralization and to develop techniques that can be used to distinguish between the morphologies, compositions, and magnetic properties of biogenic and inorganic nanocrystals. Examples of such techniques and observations are presented here.

Figure 1 shows an example of the three-dimensional morphologies of magnetite crystals within a single cell of bacterial strain MV-1 using electron tomography in the transmission electron microscope (TEM). The image was reconstructed from a tilt series of 39 high-angle annular dark field images recorded over a tilt range of $\pm 76^{\circ}$ in a Philips CM300 field emission gun TEM. Three views are shown. When magnified, the crystals show shape variations between adjacent crystals in the chain as well as rounding of crystal facets. The need for such images is illustrated by Fig. 1b, which shows the similarity of the projected outlines of crystals that have radically different morphologies.

Figure 2 illustrates the characterization of the composition of iron sulfide crystals in a multicelled magnetotactic prokaryote, in which non-magnetic mackinawite $(\mathrm{FeS})$ is thought to convert to greigite $\left(\mathrm{Fe}_{3} \mathrm{~S}_{4}\right)$ as the crystals age. During such a solid-state transformation one quarter of the iron atoms must be lost. An amorphous, iron- and oxygen-bearing shell envelops the greigite magnetosomes in Fig. 2. The presence of such an oxide shell may provide an indication that a transformation from $\mathrm{FeS}$ to $\mathrm{Fe}_{3} \mathrm{~S}_{4}$ has taken place. Figure 3 shows experimental and simulated crystal size distributions (CSDs) for iron sulfide crystals from a bacterial cell and from a sedimentary rock sample. The bacterial crystals have a Gaussian size distribution, whereas those from the rock sample have a lognormal distribution. Such distributions can provide information about the growth histories of populations of crystals, offering a possibility that biogenic iron oxides and sulfides can be distinguished from abiogenically formed iron minerals on the basis of the shapes of their CSDs [1].

References

[1] This research was supported by NASA Astrobiology grant NCC2-105 and the Royal Society. 

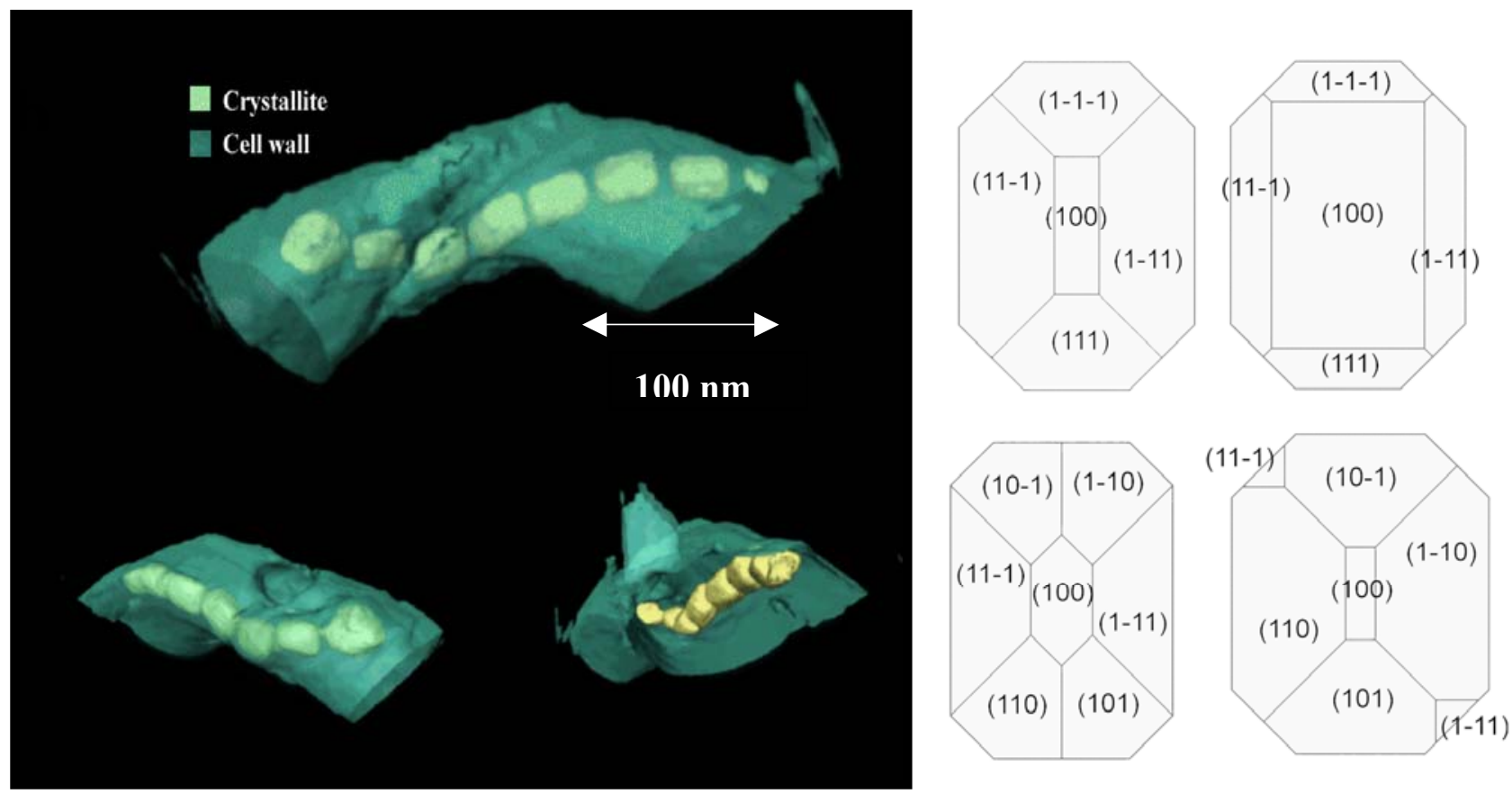

FIG. 1. a) Three views of a 3-D reconstruction of the magnetite crystals and the cell wall in a single cell of bacterial strain MV-1, obtained from a tilt series of 39 high-angle annular dark field images recorded over a tilt range of $\pm 76^{\circ}$. The scale bar applies to the top image. b) Simulated crystal projections showing the insensitivity of the crystal outline to the 3-D crystal morphology.
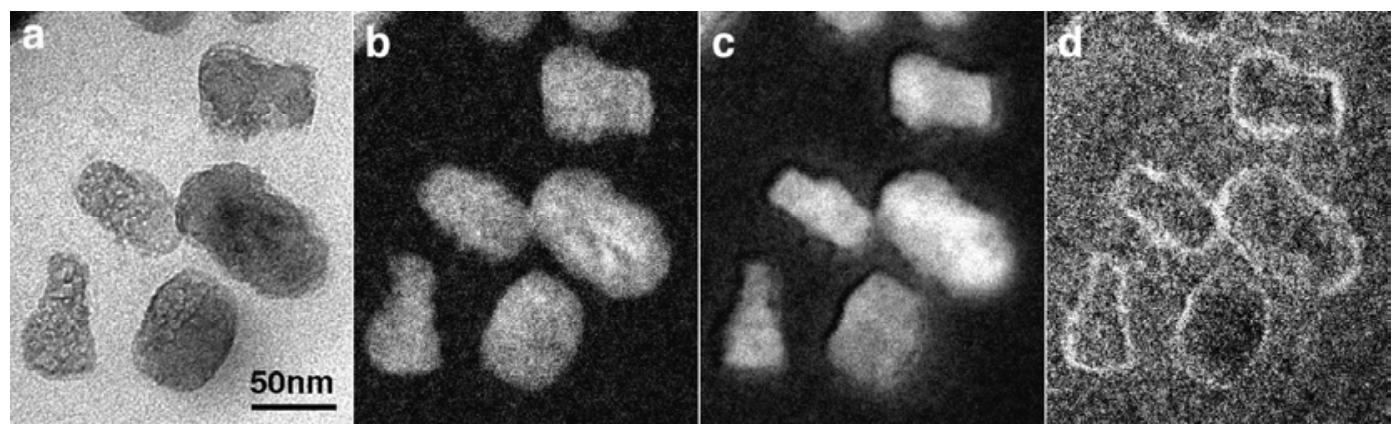

FIG. 2. a) Bright-field image, and b) to d) Fe, S and $\mathrm{O}$ three-window elemental maps of iron sulfide crystals from a multi-celled magnetic prokaryote recorded using a Gatan Imaging Filter.
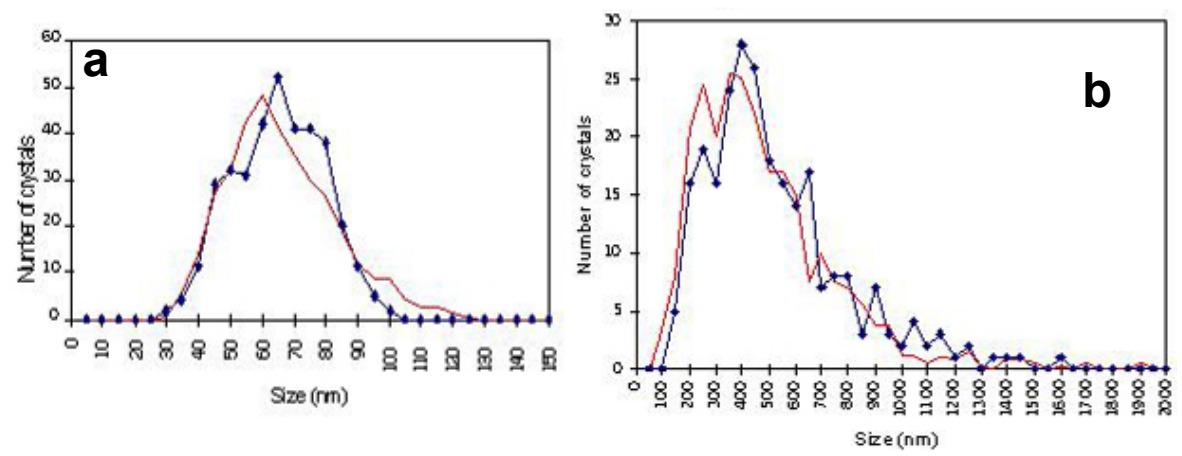

FIG. 3. Calculated (gray lines) and measured (data points and solid lines) size distributions of iron sulfide crystals from a) cells of a magnetic microorganism and b) a sedimentary rock. 